\title{
MEMORANDUM
}

No 23/2014

\section{Keep on Fighting: \\ Dynamic Win Effects in an All-Pay Auction}

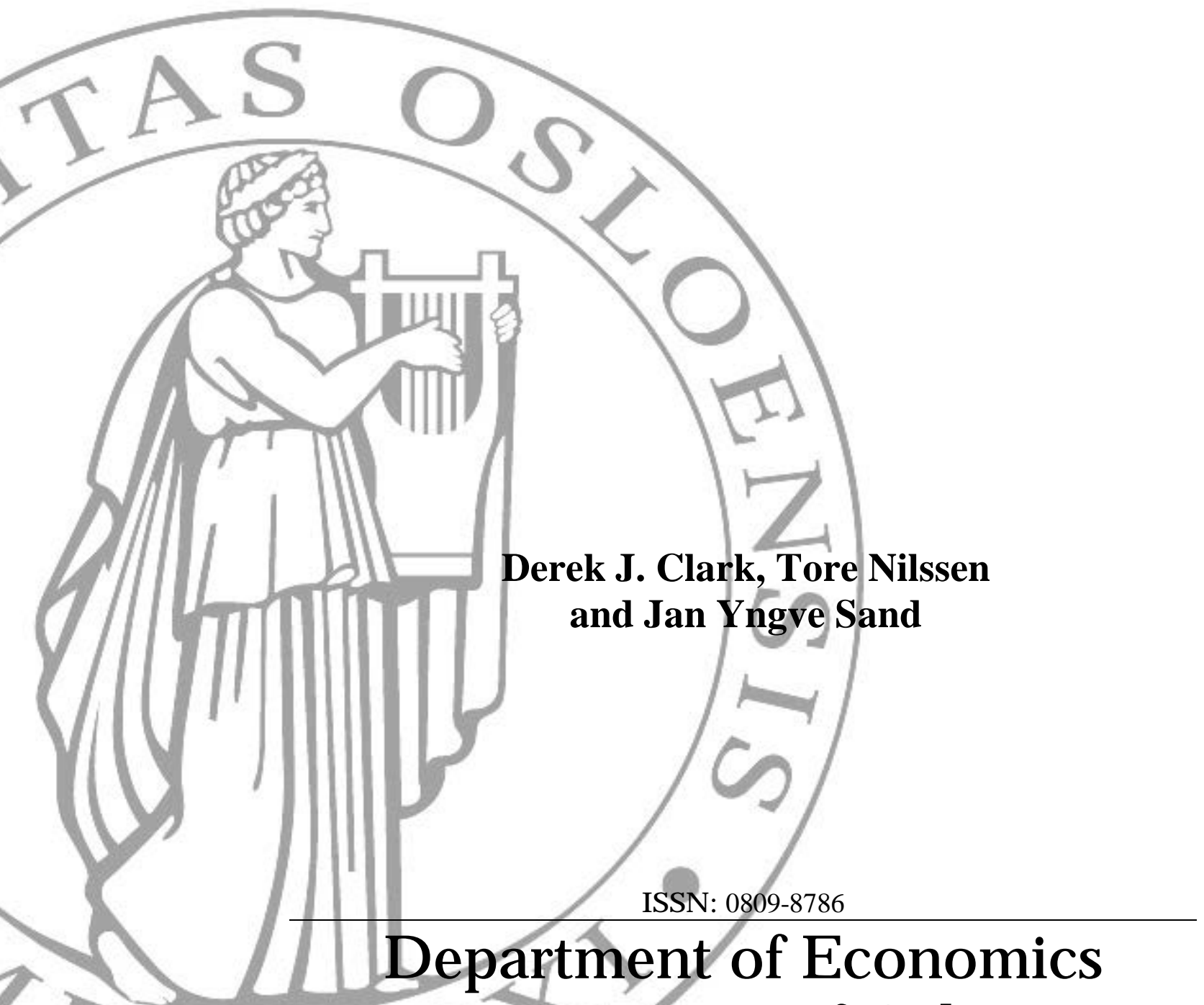

University of O slo 
This series is published by the

\section{University of Oslo \\ Department of Economics}

P. O.Box 1095 Blindern

N-0317 OSLO Norway

Telephone: + 4722855127

Fax: $\quad+4722855035$

Internet: http://www.sv.uio.no/econ

e-mail: $\quad$ econdep@econ.uio.no
In co-operation with

The Frisch Centre for Economic

Research

Gaustadalleén 21

N-0371 OSLO Norway

Telephone: $\quad$ +4722958820

Fax: $\quad+4722958825$

Internet: $\quad$ http://www.frisch.uio.no

e-mail: $\quad$ frisch@frisch.uio.no

\section{Last 10 Memoranda}

\begin{tabular}{|c|c|}
\hline No $22 / 14$ & $\begin{array}{l}\text { John K. Dagsvik and Zhiyang Jia } \\
\text { Labor Supply as a Choice among Latent Jobs: Unobserved Heterogeneity } \\
\text { and Identification }\end{array}$ \\
\hline No $21 / 14$ & $\begin{array}{l}\text { Simen Gaure } \\
\text { Practical Correlation Bias Correction in Two-way Fixed Effects Linear } \\
\text { Regression }\end{array}$ \\
\hline No $20 / 14$ & $\begin{array}{l}\text { Rolf Aaberge, Tarjei Havnes and Magne Mogstad } \\
\text { A Theory for Ranking Distribution Functions }\end{array}$ \\
\hline No $19 / 14$ & $\begin{array}{l}\text { Alice Ciccone } \\
\text { Is It All About CO2 Emissions? The Environmental Effects of Tax Reform } \\
\text { for New Vehicles in Norway }\end{array}$ \\
\hline No $18 / 14$ & $\begin{array}{l}\text { Mikolaj Czajkowski, Nick Hanley and Karine Nyborg } \\
\text { Social Norms, Morals and Self-interest as Determinants of Pro- } \\
\text { environment Behaviours }\end{array}$ \\
\hline No $17 / 14$ & $\begin{array}{l}\text { Karine Nyborg } \\
\text { Reciprocal Climate Negotiators: Balancing Anger against Even More } \\
\text { Anger }\end{array}$ \\
\hline No $16 / 14$ & $\begin{array}{l}\text { Karen Evelyn Hauge and Ole Røgeberg } \\
\text { Contribution to Public Goods as Individuals versus Group Representatives: } \\
\text { Evidence of Gender Differences }\end{array}$ \\
\hline No $15 / 14$ & $\begin{array}{l}\text { Moti Michael and Daniel Spiro } \\
\text { Skewed Norms under Peer Pressure: Formation and Collapse }\end{array}$ \\
\hline No $14 / 14$ & $\begin{array}{l}\text { Daniel Spiro } \\
\text { Resource Prices and Planning Horizons }\end{array}$ \\
\hline No $13 / 14$ & $\begin{array}{l}\text { Johan Gars and Daniel Spiro } \\
\text { Uninsurance through Trade }\end{array}$ \\
\hline
\end{tabular}

Previous issues of the memo-series are available in a PDF® format at: http://www.sv.uio.no/econ/english/research/unpublished-works/working-papers/ 


\title{
Keep On Fighting: \\ Dynamic Win Effects in an All-Pay Auction*
}

\author{
Derek J. Clark, Tore Nilssen, and Jan Yngve Sand ${ }^{\dagger}$
}

\section{Memo 23/2014-v2}

(This version June 30, 2015)

\begin{abstract}
We investigate a multi-period contest model in which a contestant's present success gives an advantage over a rival in the future. How this win advantage affects contestants' efforts, and whether the laggard gives up or keep on fighting are key issues. We find that the expected effort of the laggard will always be higher than the rival at some stage in the series of contests, and this is most likely to happen when at a large disadvantage or at a late stage in the series.
\end{abstract}

Keywords: contest; all-pay auction; win advantage.

JEL codes: D74, D72

${ }^{*}$ We are grateful for comments received at a seminar at the University of Oslo. Nilssen's research has received funding from the ESOP Centre at the University of Oslo. ESOP is supported by the Research Council of Norway through its Centres of Excellence funding scheme, project number 179552.

${ }^{\dagger}$ Clark: School of Business and Economics, University of Troms $\varnothing$, NO-9037 Troms $\varnothing$, Norway; derek.clark@uit.no. Nilssen: Department of Economics, University of Oslo, P.O. Box 1095 Blindern, NO-0317 Oslo, Norway; tore.nilssen@econ.uio.no. Sand: School of Business and Economics, University of Troms $\varnothing$, NO-9037 Troms $\varnothing$, Norway; jan.sand@uit.no. 


\section{Introduction}

Winning a competition may result not only in a prize, but also an advantage in subsequent competitions. Consider, for example, competitions for research grants. While the successful applicant for a grant may harvest all the direct benefits that the research money awarded provides, there may also be an extra benefit from winning: carrying out the research that the original grant facilitated makes for increased chances to win in future grant competitions. In this way, an early competition for a prize implies that there will be advantaged and disadvantaged participants in subsequent competitions. The question is how contestants' incentives to put in effort in such sequential competitions vary over time as successes and failures are recorded.

In order to understand the dynamics of competitions with win advantages, we develop in this paper a two-player, multi-period contest model where, in each period, there is a prize to win. In this model, a win in today's contest implies a headstart in future contests. We point out two forces that interact in explaining contestants' incentives across time. On one hand, starting from a symmetric situation, a win to one contestant lowers both players' incentives to put in effort, but more so for the disadvantaged player - the laggard. This is because the headstart enables the advantaged player - the leader - to lay back a bit and still stand a good chance to win again, so that also the laggard pulls back somewhat.

On the other hand, there is an extra value of winning for the leader, since a win means he will also be a leader in the future, while a win for the laggard will at best even the score. This extra value dampens the laggard's incentives to put in effort. However, the value of winning falls over time in a finite game, simply because there are fewer future contests left. Eventually, therefore, the disincentives for the leader from having headstart dominates the laggard's disincentives from facing an opponent with an extra value from winning, so that, towards the end of the sequence of contests, the laggard will be the high performer.

Above, we mentioned one instance of a dynamic win advantage, one that occurs in competitions for research grants: Winning an early grant enhances the chance to win again in the competition for later grants. But such win advantages can also be expected to occur in a number of other contexts. In sales-force management, it is customary to give awards to the Seller of the Month and the like. And in such sales forces, it is not uncommon for the more successful agents to be given less administrative duties, better access to back-office resources, more training than the less successful, and better territories; see, e.g., Skiera and Albers (1998), Farrell and Hakstian (2001), and Krishnamoorthy, et al. (2005). Another source of win advantage could be successful agents having access to different prizes 
than less successful ones (Megidish and Sela, 2014). A further source of win advantage may be psychological (Krumer, 2013). Experimental studies by Reeve, et al., (1985) and Vansteenkiste and Deci (2003) show that winners feel more competent than losers, and that winning facilitates competitive performance and contributes positively to an individual's motivation. ${ }^{1}$

The sequence of contests that we model in this paper gives, as noted, rise to the creation of a leader and a laggard based on dynamic win advantages. Another model of multi-period contests featuring leaders and laggards is that of a race, or a best-of- $t$ contest. In a race, the overall winner is the first to win $t$ stage contests; see Harris and Vickers (1987) for an early analysis and Konrad (2009) for an overview. ${ }^{2}$ Naturally, the winner of the first stage becomes the leader in the second, in the sense of having fewer stages left to complete the game. This leader has a much firmer grip on the rest of the game than the leader has in our context. Results differ in the two set-ups, not surprisingly. While the laggard is strongly discouraged in a race, he is much more interested in staying and keep on fighting in our setting. ${ }^{3}$

Two particularly relevant analyses of races are by Konrad and Kovenock (2009) and Krumer (2013). Both these studies include prizes in the stage game, in addition to the grand prize to the overall winner, and show how such stage prizes mitigate the laggard's discouragement, a result which is in line with what we find here. Krumer (2013) introduces, in addition, a win advantage in that the loser of the first contest gets handicapped in the second. ${ }^{4}$

In Clark, et al. (2015) we explore the consequences of dynamic win advantage, similar to the one we study here, when players meet in a sequence of Tullock contests. In Clark and Nilssen (2013), the advantage in future contests does not stem from winning today, but rather from efforts exerted today.

The paper is organized as follows. Section 2 presents the model, whereas Section 3 looks at a single-stage contest with an advantaged player. With the help of the preliminary results in Section 3, the equilibrium is then characterized in Section 4. In Section 5, we go on to discuss various aspects

\footnotetext{
${ }^{1}$ Note also empirical evidence indicating that laggards can exert more effort than leaders: Tong and Leung (2002) on experiments and Berger and Pope (2011) on basketball games.

${ }^{2}$ Another interesting multi-period contest creating a leader and a laggard is the incumbency competition, where the leader at contest $t$ is the winner of contest $t-1$; see Ofek and Sarvary (2003) and Mehlum and Moene (2006, 2008).

${ }^{3}$ But see Section 6.4, where we discuss how long games in our set-up have race-like features, in the sense that the laggard might get discouraged towards the end.

${ }^{4}$ In Section 6.1 below, we extend our model to discuss a win advantage that is in part a headstart for the winner in future contests, as we have in our main analysis, and in part a handicap on the loser, as in Krumer (2013).
} 
of how the equilbrium play evolves in this game. In Section 6, we present a number of extensions to our analysis. In particular, we discuss win advantages as headstarts versus handicapping in Section 6.1, the effect of players' discounting future payoffs in Section 6.2, games where stage prizes vary across time in Section 6.3, and long games in Section 6.4. Section 7 concludes. The proofs of most of our results, as well as some elaborations, are relegated to an Appendix.

\section{Sequential contests}

There are two identical players, $i=1,2$, who compete in a series of $T \geq 2$ all-pay auctions for a prize of $v$ in each contest by making irreversible outlays $x_{i, t} \geq 0, t=1,2, \ldots, T$. The probability of winning for player 1 in contest $t$ depends on current effort as well as on the history so far, summarized by the number of wins that player 1 has in the previous $t-1$ contests. Every previous win makes it possible for him to win the current contest with less effort. In particular, the score for player 1 in contest $t$ is given by the sum of his current effort $x_{1, t}$ and his cumulated win advantage that winning previous contests confers on him. Denote the win advantage from winning a previous contest by

$$
s \in\left(0, \frac{v}{T-1}\right)
$$

The upper bound is there to make sure that no subgame can occur in which no effort is exerted. ${ }^{5}$

After having won $m_{t}$ of the previous $t-1$ contests, player 1 has a current contest score of $x_{1, t}+m_{t} s$, whilst the other player has a score of $x_{2, t}+\left(t-1-m_{t}\right) s$. The contestant with the larger score wins the current contest; in particular, player 1 wins if $x_{1, t}+m_{t} s>x_{2, t}+\left(t-1-m_{t}\right) s$. The win probability for player 1 in contest $t$ can thus be written as:

$$
p_{1, t}=\left\{\begin{array}{l}
1 \text { if } m_{t} s+x_{1, t}>\left(t-1-m_{t}\right) s+x_{2, t} \\
\frac{1}{2} \text { if } m_{t} s+x_{1, t}=\left(t-1-m_{t}\right) s+x_{2, t} \\
0 \text { if } m_{t} s+x_{1, t}<\left(t-1-m_{t}\right) s+x_{2, t}
\end{array}\right.
$$

where $m_{1}=0$. The probability of player 2 winning is defined similarly.

For the analysis that follows, it is convenient to think of the net number of wins that a player has achieved. For player 1 , define this as $M_{t}:=$ $m_{t}-\left(t-1-m_{t}\right)=2 m_{t}-t+1$. Without loss of generality, we shall assume that $M_{t} \geq 0$. Now the probability that player 1 wins contest $t$ can be written

\footnotetext{
${ }^{5}$ See Sections 6.3 and 6.4 for discussions of some cases where this restriction is lifted.
} 


$$
p_{1, t}=\left\{\begin{array}{c}
1 \text { if } M_{t} s+x_{1, t}>x_{2, t} \\
\frac{1}{2} \text { if } M_{t} s+x_{1, t}=x_{2, t} \\
0 \text { if } M_{t} s+x_{1, t}<x_{2, t}
\end{array}\right.
$$

Thus, having the larger number of net wins in the past gives player 1 a headstart in contest $t$, and increasingly so the more net wins he has.

At contest $t$, the maximum number of net wins for player 1 is $t-1$, meaning that this player has won all of the previous $t-1$ contests. If player 1 has won all but one of the previous $t-1$ contests, then his net win advantage is $t-3$, whereas the net win advantage is $t-5$ if player 1 has won all but two of the previous contests, and so on.

\section{A single contest with advantage}

To get to grips with the series of contests, it is instructive to first look at one. Consider a single all-pay auction contest in which one player is advantaged in the double sense of achieving a probability of winning with a lower effort than the rival and having a larger value of the prize if he wins. Two players compete over a prize of value $v_{1}=v+a$ for player 1 and $v_{2}=v$ for player 2 , where $v>0$ and $a \geq 0$, by making irreversible outlays $x_{i}, i=1,2$; the marginal cost of an outlay is fixed at 1 . The probability that player 1 wins is given by

$$
p_{1}=\left\{\begin{array}{l}
1 \text { if } z+x_{1}>x_{2} \\
\frac{1}{2} \text { if } z+x_{1}=x_{2} \\
0 \text { if } z+x_{1}<x_{2}
\end{array},\right.
$$

where $z \geq 0$ is a bias parameter indicating a headstart to player 1 . The expected payoff for player 1 is then given as

$$
E \pi_{1}=\left[\operatorname{Pr}\left(z+x_{1}>x_{2}\right)+\frac{1}{2} \operatorname{Pr}\left(z+x_{1}=x_{2}\right)\right] v_{1}-x_{1},
$$

with that of player 2 defined similarly.

Let $F_{i}\left(x_{i}\right)$ be the cumulative distribution function of player $i$ 's mixed strategy, $i=1,2$. The following Proposition characterizes the unique Nash equilibrium (Clark and Riis, 1995; Konrad, 2002).

Proposition 1 i) If $z \geq v$, then $x_{1}=x_{2}=0$.

ii) If $z<v$, then the unique mixed-strategy Nash equilibrium of the game is

$$
\begin{aligned}
& F_{1}(0)=\frac{z}{v} ; \quad F_{1}\left(x_{1}\right)=\frac{z+x_{1}}{v}, \quad x_{1} \in[0, v-z] ; \\
& F_{2}(0)=\frac{z+a}{v+a} ; \quad F_{2}\left(x_{2}\right)=\frac{x_{2}+a}{v+a}, \quad x_{2} \in[z, v] .
\end{aligned}
$$


In this equilibrium, the expected amounts of effort of the players are

$$
E x_{1}^{*}=\frac{(v-z)^{2}}{2 v}, \text { and } E x_{2}^{*}=\frac{v^{2}-z^{2}}{2(v+a)} ;
$$

expected net surpluses are

$$
E \pi_{1}^{*}=z+a, \text { and } E \pi_{2}^{*}=0
$$

and probabilities of winning are

$$
p_{1}^{*}=1-\frac{v^{2}-z^{2}}{2 v(v+a)}, \text { and } p_{2}^{*}=\frac{v^{2}-z^{2}}{2 v(v+a)} .
$$

Quite unsurprisingly, we see from (7) that the advantaged player has more to gain from the contest. More interestingly, we see from (4) and (5) that the disadvantaged player 2 on one hand has a higher probability of being inactive but that he, conditional on being active, has a higher expected effort. This translates, by way of (6), into the following:

Corollary 1 The disadvantaged player has the larger expected effort of the two if and only if

$$
a<\frac{2 v z}{v-z} .
$$

This says that the laggard has more effort than his rival when his disadvantage in terms of the value of winning is sufficiently weak relative to the prize and the disadvantage in terms of the win probability. This is evident from (4) and (5): whereas $v$ and $z$ affect the two players more or less in the same manner, $a$ affects the disadvantaged player's effort only the more disadvantaged he is in terms of the value of winning, the higher is the probability that he is inactive.

These results are used in the next sections to solve and analyze our model. In terms of the series of contests, $z$ relates to the win advantage in a particular contest, whilst $a$ will be the extra amount that the leader can win in the continuation of the game.

\section{Equilibrium}

The model is solved by backwards induction to find a Nash equilibrium at each stage of the game, using the results from the previous section. We present the structure of the solution for contest $T$, and then for a contest $t \geq 2$, before solving for the first contest, and thus for the full game. 
Consider first the final contest $T$. Let expected payoff be given by the function $u_{i, T}\left(M_{T}\right)$. Since this is the end of the game, expected payoffs for the leader and laggard, respectively, are

$$
\begin{aligned}
& u_{1, T}\left(M_{T}\right)=p_{1, T} v-x_{1, T} \\
& u_{2, T}\left(M_{T}\right)=\left(1-p_{1, T}\right) v-x_{2, T} .
\end{aligned}
$$

In the language of Proposition 1 , this is a case where $a=0$ and $z=$ $M_{T} s$. Thus, expected efforts and payoffs in equilibrium are

$$
\begin{aligned}
& E x_{1, T}^{*}\left(M_{T}\right)=\frac{\left(v-M_{T} s\right)^{2}}{2 v}, \quad E x_{2, T}^{*}\left(M_{T}\right)=\frac{v^{2}-\left(M_{T} s\right)^{2}}{2 v} ; \\
& E u_{1, T}^{*}\left(M_{T}\right)=M_{T} s, \quad E u_{2, T}^{*}\left(M_{T}\right)=0 .
\end{aligned}
$$

Note that, from (9) - and in line with Corollary 1 - we can state the following:

Corollary 2 The laggard has the higher effort in the last contest for any $M_{T} \geq 1$.

Furthermore, total expected effort in contest $T$ is

$$
E x_{1, T}^{*}\left(M_{T}\right)+E x_{2, T}^{*}\left(M_{T}\right)=v-M_{T} s .
$$

If $M_{T}=0$, so that each player has won equally many of the previous contests, then the game in this last contest is symmetric and we have

$$
\begin{aligned}
& E x_{1, T}^{*}\left(M_{T}=0\right)=E x_{2, T}^{*}\left(M_{T}=0\right)=\frac{v}{2} ; \\
& E u_{1, T}^{*}\left(M_{T}=0\right)=E u_{2, T}^{*}\left(M_{T}=0\right)=0 .
\end{aligned}
$$

Consider next any contest $t \in\{2, \ldots, T-1\}$ in which $M_{t} \geq 1$, i.e., player 1 has at least one more win than player 2 so far. The expected payoff for player 1 is now given by:

$$
E u_{1, t}\left(M_{t}\right)=p_{1, t}\left[v+E u_{1, t+1}^{*}\left(M_{t}+1\right)\right]+\left(1-p_{1, t}\right)\left[E u_{1, t+1}^{*}\left(M_{t}-1\right)\right]-x_{1, t} ;
$$

That is, either he wins, receives the prize $v$ for this contest, and improves his score; or he loses, receives no prize, and worsens his score. Quite straightforwardly, we can rewrite this as

$$
E u_{1, t}\left(M_{t}\right)=E u_{1, t+1}^{*}\left(M_{t}-1\right)+p_{1, t}\left(v+a_{t}\right)-x_{1, t},
$$

where

$$
a_{t} \equiv E u_{1, t+1}^{*}\left(M_{t}+1\right)-E u_{1, t+1}^{*}\left(M_{t}-1\right) .
$$

Note that, if $M_{t}=1$, then $E u_{1, t+1}^{*}\left(M_{t}-1\right)=0$, since contest $t+1$ becomes symmetric if the advantaged player 1 loses contest $t$ in this case. 
Player 2 is at a disadvantage, being at least one net win down. If he wins the current contest, then he gains the stage prize $v$ and improves his score, or rather worsens the score of his rival. But even with a win, he will continue as the disadvantaged player earning zero, or at best - if winning at $M_{t}=1$ - getting even, but still earning zero. Thus, the payoff to player 2 is given by

$$
E u_{2, t}\left(M_{t}\right)=\left(1-p_{1, t}\right) v-x_{2, t} .
$$

At contest $t, z=M_{t} s$ measures the bias in the probability of winning, and $a=a_{t}$ is the extra prize that player 1 has, relative to player 2 , from winning the current stage. Note that the advantaged player has an expected gross payoff of $E u_{1, t+1}^{*}\left(M_{t}-1\right)$, no matter the outcome of the stage contest.

If $M_{t}=0$, then the game is symmetric. Neither player has a bias in the win probability, implying that the expected equilibrium payoff from the current stage is zero. In this case, the expression for player $i$ 's payoff needs to be modified to

$$
E u_{i, t}\left(M_{t}=0\right)=p_{i, t}\left[v+E u_{1, t+1}(1)\right]-x_{i, t},
$$

since the continuation payoff of losing from this state is 0 . In this case, the contest is symmetric over a prize of $v+E u_{1, t+1}(1)$ for each player, and each player has an expected effort of

$$
\frac{1}{2}\left[v+E u_{1, t+1}(1)\right]
$$

with an expected payoff of 0 . Since, by definition, $M_{1}=0$, (11) holds for the first contest at $t=1$.

Proposition 2 summarizes the equilibrium expected efforts and expected payoffs of the $T$ sequential contests. The proof, which is based on Proposition 1, is in the Appendix.

Proposition 2 In a contest $t \in\{2, \ldots, T\}$ with $M_{t} \geq 1$, equilibrium expected efforts of the players are

$$
\begin{aligned}
E x_{1, t}^{*}\left(M_{t}\right) & =\frac{\left(v-M_{t} s\right)^{2}}{2 v} \\
E x_{2, t}^{*}\left(M_{t}\right) & =\frac{v^{2}-\left(M_{t} s\right)^{2}}{2[v+2 s(T-t)]}
\end{aligned}
$$

with equilibrium expected payoffs

$$
\begin{aligned}
& E u_{1, t}^{*}\left(M_{t}\right)=s(T-t+1)\left[M_{t}+\frac{1}{2}(T-t)\right], \\
& E u_{2, t}^{*}\left(M_{t}\right)=0 .
\end{aligned}
$$


In a contest $t$ with $M_{t}=0$, including contest 1 , equilibrium expected efforts and payoffs are

$$
\begin{aligned}
& E x_{i, t}^{*}(0)=\frac{1}{2}\left[v+\frac{1}{2} s(T-t)(T-t+1)\right] \\
& E u_{i, t}^{*}(0)=0 ; \quad i=1,2 .
\end{aligned}
$$

Note, from (15), that there is a hard fight to win the first contest, where total expected efforts are $v+\frac{1}{2} s T(T-1)$.

\section{Analysis}

Below, we present a number of results on the equilibrium established in Proposition 2. Our first results concern equilibrium behavior at or near symmetry, whereas subsequent results focus on equilibrium play in various cases of asymmetry.

At the outset, $t=1$, the contest is symmetric. As is clear from (15), the contestants have expected efforts that far exceed the value of the stage prize $v$, since they both want to become the advantaged player in contest 2 , with the possibility of compounding this early win advantage. The expected payoff in equilibrium for the game as a whole is zero, so that the players compete away the whole surplus in the course of the game. This leads to the following Corollary to Proposition 2.

Corollary 3 Total expected efforts over the $T$ contests are $v T$.

In any symmetric state, where $M_{t}=0$, equation (15) indicates that there is intense competition to get the game onto a favorable track. The winner of the contest in a symmetric state will enter the continuation a leader, while the loser becomes laggard. With these roles being assigned in this manner, incentives to provide efforts fall. In fact, we have the following.

Corollary 4 Suppose there is symmetry in contest $t \in\{1, \ldots, T-1\}$, i.e., $M_{t}=0$. Then

(i) total expected efforts in contest $t$ are greater than $v$; and

(ii) total expected efforts in contest $t+1$ are less than $v-s$.

Actually, there can be symmetry only in odd-numbered contests: It is only when $t-1$ is even that the gross number of previous wins can be the same for the two players at contest $t$ so that symmetry entails. As time goes by, symmetry means less expected efforts. This is seen directly from (15) which is decreasing in $t$. We have:

Corollary 5 Total expected efforts in symmetric contests, where $M_{t}=0$, decrease over time. 
Intuitively, the less future there is after a contest, the less value there is to becoming the leader. To illustrate this, consider an example.

Example $1 v=1, T=8, s=0.05$

Write $E X_{t}^{*}(0)=E x_{1, t}^{*}(0)+E x_{2, t}^{*}(0)$. This gives the following table of total expected effort for tied states:

\begin{tabular}{|c|c|}
\hline Contest & $E X_{t}^{*}(0)$ \\
\hline 1 & 2.4 \\
\hline 3 & 1.75 \\
\hline 5 & 1.3 \\
\hline 7 & 1.05 \\
\hline
\end{tabular}

We turn next to asymmetric contests. When asymmetry occurs, two factors play a role: the bias in the probability function, $z_{t}=M_{t} s$, and the difference $a_{t}$ in the value of winning between the two players. As shown in the Appendix, the latter equals ${ }^{6}$

$$
a_{t}=2 s(T-t) .
$$

Remarkably, it does not depend on how big the lead of the leader is, i.e., on $M_{t}$. But it does increase in both the time left at $t$ and the win advantage $s$. Whereas an increase in the bias $z_{t}$ decreases the expected efforts of both players, increasing the value difference $a_{t}$ only affects the expected effort of the laggard, and negatively so, according to Proposition 1. Hence, the lead in contest $t$, as measured by $M_{t}$, reduces the expected effort of both the leader and the laggard; whereas the fact that the leader has more to gain due to a positive continuation payoff only reduces the effort of the laggard.

The expected payoff of the advantaged player from contest $t$ has a simple form, as indicated by (14). In this expression, $T-t+1$ is the number of contests remaining when we reach contest $t$. Hence, the expected payoff in equilibrium to the player with a net win advantage is conveniently expressed as a function of the number of remaining contests, the number of net wins at that stage, and the size of the advantage per win.

When it comes to the relative expected efforts of the leader and the laggard, we can use Proposition 2 together with Corollary 1 to show the following two results:

Corollary 6 In any contest $t \geq 2$ where $M_{t} \geq 1$, the laggard has higher expected effort than the leader if and only if

$$
T-t<\frac{v M_{t}}{v-M_{t} s} .
$$

\footnotetext{
${ }^{6}$ See the proof of Proposition 2 in the Appendix.
} 
Corollary 7 When $T=3$, the expected effort of the laggard is larger than the leader at $t=2$.

Together, Corollaries 2 and 7 deal with cases of short series of contests. When the series consists of two contests, the laggard will always exert more effort in expectation than the leader in the final contest. When the series consists of three contests, the laggard will always have more expected effort than the leader in the second contest, and also in the final one, should he still be disadvantaged at this stage. From (12) and (13), it can be verified that the win advantage, as measured by $M_{t}$, reduces the expected effort of the leader by more than the laggard. Modifying this effect is the fact that the winner of the first contest has more to fight for, as measured by $a_{2}$, which is zero when $T=2$, and $2 s$ when $T=3$. Hence there is no effect on the expected effort of the laggard through this channel in the former case, and a negative effect in the latter. In sum, however, the expected effort of the leader falls more in such short series of contests.

Corollary 6 deals with the more general case. From this we can conclude that the laggard in expectation has more effort than the leader in cases where

- he is at a large disadvantage (large $M_{t}$ ),

- there are a low number of contests left (low $T-t)$,

- the win advantage is high, and

- the stage prize $v$ is low.

These results reflect the findings in Section 3 above: When there are relatively few contests left, the difference in valuation between winning and losing, $a_{t}$, becomes small. The value of $a_{t}$ affects the laggard's effort negatively but does not affect the leader's effort, whereas the bias $M_{t}$ affects both expected efforts negatively. It can easily be verified that the negative effect that increasing $M_{t}$ has on the leader's effort is larger in magnitude than the reduction in that of the laggard. Hence the leader slacks off by more than the laggard is discouraged following an increase in the net win. The role of the size of the win advantage $s$ is more subtle, since it leads to more bias in the contest success function, causing less effort by both competitors, at the same time as it increases $a_{t}$ which reduces only the laggard's effort. The larger is $s$, the more $a_{t}$ falls in each successive contest, which raises the effort of the laggard. Hence, although increases in $M_{t}$ and $s$ lead to a higher likelihood that the laggard will have more effort, they work through different channels.

Our results are partly driven by the fact that competitors can win a prize at each stage. This will generally raise the expected effort level for 
both players. The comparative-static properties of (12) and (13) show that an increase in $v$ will tend to raise the expected effort of the leader relative to the follower when there are many contests left, and that the laggard's effort will be raised the most in later stages of the contest. Early in the series of contests, a leader has a great deal to fight for, since $a_{t}=2 s(T-t)$ is large, and increasing $v$ strengthens this effect. Later on, $a_{t}$ falls, giving the laggard more to fight for.

The following Proposition sums up results on how the relative expected efforts of leader and laggard develop for games of more than three rounds; the proof is in the Appendix.

Proposition 3 Suppose $T \geq 4$.

(i) There is always one contest $t$ in the series such that $t \leq T-1$, $M_{t} \geq 1$, and $E x_{2, t}^{*}\left(M_{t}\right)>E x_{1, t}^{*}\left(M_{t}\right)$.

(ii) If $t \leq T-1, M_{t} \geq 1$, and $E x_{2, t}^{*}\left(M_{t}\right)>E x_{1, t}^{*}\left(M_{t}\right)$, then $E x_{2, t+1}^{*}\left(M_{t}+1\right)>$ $E x_{1, t+1}^{*}\left(M_{t}+1\right)$.

(iii) If $\leq T-2, M_{t} \geq 2$, and $E x_{2, t}^{*}\left(M_{t}\right)>E x_{1, t}^{*}\left(M_{t}\right)$, then $E x_{1, t+1}^{*}\left(M_{t}-1\right)>$ $E x_{2, t+1}^{*}\left(M_{t}-1\right)$.

(iv) If $t \leq T-1, M_{t} \geq 2$, and $E x_{2, t}^{*}\left(M_{t}\right)>E x_{1, t}^{*}\left(M_{t}\right)$, then it is possible to have $\operatorname{Ex}_{1, t+1}^{*}\left(M_{t}-1\right)>E x_{2, t+1}^{*}\left(M_{t}-1\right)$.

Part (i) of this Proposition states that the expected effort of a laggard will always be larger than that of the advantaged player at some stage in the series of contests before the final stage. The intuition is based upon the combination of two effects: the bias which reduces both efforts, and that of the leader more, and the reduction in the continuation payoff for the leader in the series, which encourages the laggard.

Part (ii) states that, if the laggard has more expected effort in contest $t$ and loses, then he will also have more expected effort in the following contest. The transition from contest $t$ to $t+1$ here implies an increased win bias causing more slacking off by the leader, while the progression of the contest lowers the continuation value of the leader.

Part (iii) looks at the case in which the leader has the more expected effort in contest $t$; should he lose this contest, then, given that he is still advantaged, he will continue to have the more effort in the next contest, as long as the game by then has not reached the final contest; recall that the laggard always has more effort in contest $T$. In this case, the transition of the contest from $t$ to $t+1$ implies a smaller win bias; both expected efforts increase, affecting the leader more.

Part (iv) looks at the case in which the laggard has more expected effort in a contest; if he wins the contest and is still disadvantaged, then it is possible for this player to have less expected effort than the rival in the next contest. 
Parts (ii) and (iii) of Proposition 3 can be combined to show that the sign of the difference in efforts of the players is invariant to loss in the following sense:

Corollary 8 Suppose $T \geq 4$. Irrespective of who has the more expected effort in contest $t$, with $M_{t} \geq 2$, if this player loses that contest, then he will have more expected effort also in contest $t+1$, unless $t=T-1$.

Many trajectories of the game are possible, of course, depending upon who wins each stage. One extreme case is that of the "unluckiest loser", i.e., a player who has lost each contest to date; correspondingly, his opponent is the "luckiest winner". Suppose that, at the start of contest $t$, player 2 has lost each previous contest so that $M_{t}=t-1$. Despite his bad luck, he will never give up, however. In fact, as Corollary 2 shows, he will eventually have the higher expected effort, even after a losing streak. And Corollary 7 tells us that, for $T=3$, the unluckiest loser will have the higher expected effort already at contest 2 . The next two Propositions extend this discussion to longer series of contests.

Proposition 4 notes that, if the condition in (1) is strengthened, then the expected efforts of the leader and the laggard in this trajectory move in opposite directions over time.

Proposition 4 Suppose that, at every contest $t, M_{t}=t-1$, meaning the same player wins all contests.

(i) The luckiest winner's expected effort decreases over time.

(ii) If

$$
s(T-1) \leq \frac{v}{2}
$$

then the unluckiest loser's expected effort increases over time.

As we see from (12) and (13), increasing the leader's advantage by an increase from $M_{t}$ to $M_{t+1}=M_{t}+1$ lowers both players' expected efforts. But at the same time, this decreases the value of being leader, which again lifts the unluckiest loser's effort. Under the condition in (19), the latter effect is the stronger and the unluckiest loser puts in more and more effort over time, in expectation.

Proposition 5 shows that, even without the condition in (19), there will always come a time, before the penultimate contest, at which the effort of the unluckiest loser outstrips that of his winning opponent. Furthermore, the laggard who keeps losing will have more expected effort for the duration of the contest. The proofs of both these Propositions are in the Appendix.

Proposition 5 Suppose that $T \geq 5$. 
(i) There exists a $\widehat{t} \in\{3, \ldots, T-2\}$ such that, if $M_{t}=t-1$ for some $t \in$ $\{2, \ldots, T\}$, then $\operatorname{Ex}_{1, t}^{*}\left(M_{t}\right)>\operatorname{Ex}_{2, t}^{*}\left(M_{t}\right)$ if $t<\widehat{t}$, and $\operatorname{Ex}_{2, t}^{*}\left(M_{t}\right)>\operatorname{Ex}_{1, t}^{*}\left(M_{t}\right)$ if $t>\widehat{t}$.

(ii) The time $\widehat{t}$ is weakly decreasing in s. It is also weakly increasing in $T$, at a rate less than 1 .

In part (i) of Proposition 5, we find a contest, denoted by $\widehat{t}$, such that the expected effort of the unluckiest loser will outstrip that of the leader. Furthermore, continuing to lose gives a higher effort in expectation from the laggard.

The first effect in part (ii) of Proposition 5 says that the crossing of expected effort will be earlier, the higher is $s$. This is due to the fact that a large $s$ gives both a large win bias in the contest success function and a large continuation value of winning to the leader. The former effect makes both players exert less effort, with the larger effect on the leader. The latter effect makes the leader's continuation value fall quickly so that the leader has less to gain from successive wins. This encourages even the unluckiest loser.

That $\widehat{t}$ is weakly increasing in $T$ means that the larger the total number of contests in the game, the longer it will take before the effort of the unluckiest loser is larger than the leader. However, the number of periods remaining when this happens is also larger the total number of contests since, by part (ii) of Proposition 5, T- $t$ is weakly increasing in $T$.

The two Propositions are illustrated in Figure 1, where we record the expected efforts of the unluckiest loser and the luckiest winner for our Example, where $T=8, v=1$, and $s=0.05$; note that the example satisfies condition (19).

Initially both players have a high expected effort in order to become the advantaged player from contest 2 on. After this, the expected effort of each player falls, with the loser of the first contest having the larger fall. As the bias increases, the luckiest winner decreases expected effort successively; this effect also exerts downward pressure on the expected effort of the laggard, but the positive effect - that winning matters less and less to the advantaged player - outweighs this. Hence, the effort of the laggard increases across contests. In the example, the unluckiest loser has the larger expected effort in each period from $t=5$ on.

Figure 2 plots the number of contests remaining from the time at which the effort of the laggard is largest (denoted $\mathrm{R}$ in the figure), using as before $v=1, s=0.05$. When $T=8$, there are three contests remaining after crossing (as illustrated in Figure 1); when $T=15$, there are eight remaining contests, and so on. 


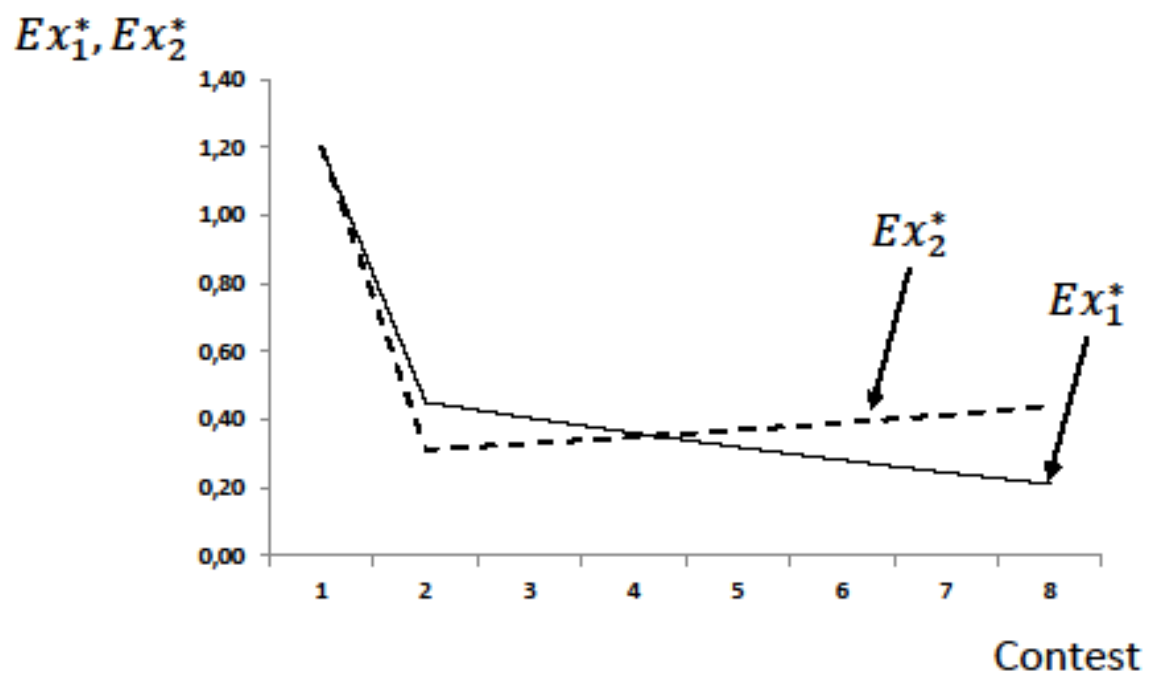

Figure 1: Expected efforts in the case of the unluckiest loser.

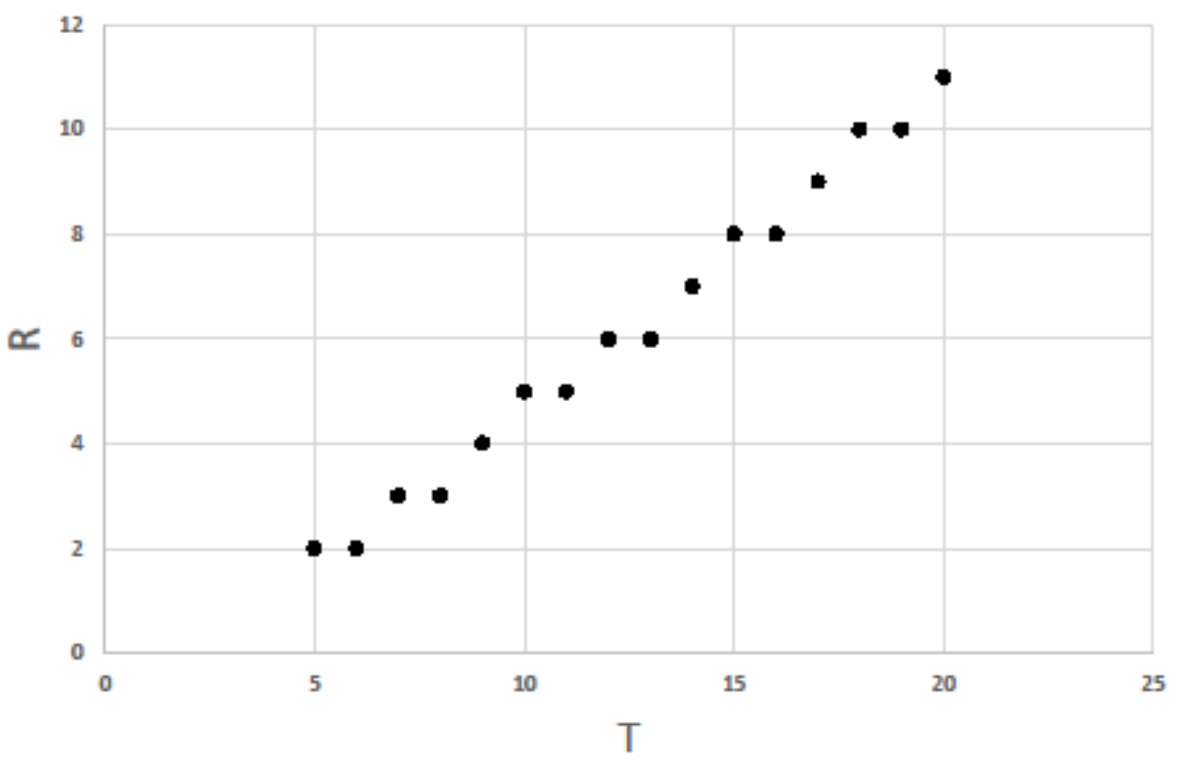

Figure 2: Remaining contests after unluckiest-loser effort is larger. 


\section{Extensions}

In this Section, we discuss four departures from the basic model. In Section 6.1 , we allow the win advantage to materialize as a combination of headstart and handicapping, thus departing from the contest success function in (2). In Section 6.2, we discuss how the equilibrium would be affected by players discounting future payoffs. In the final two sections, we depart in various ways from the assumption in (1) that put a restriction on how the win advantage, the length of the game, and the stage prize are related. In Section 6.3, we study a sequence of all-pay auctions where prizes vary across time, making it necessary to allow the prize in a single contest to breach that assumption. In Section 6.4, we consider long games, where $T \geq \frac{v}{s}+1$.

\subsection{Headstart vs handicapping}

In our main analysis, the effect of a win in today's contest is to create a headstart for the winner in future contests. It can be argued that this is a narrow view of such a win advantage. An alternative is to allow for the win advantage to take the form in part of a headstart for the winner and in part of a handicap for the loser. In order to model this, let us replace the contest success function in (2) with the following:

$$
p_{1, t}=\left\{\begin{array}{l}
1 \text { if } b M_{t} s+x_{1, t}>\left[1-(1-b) M_{t} s\right] x_{2, t} \\
\frac{1}{2} \text { if } b M_{t} s+x_{1, t}=\left[1-(1-b) M_{t} s\right] x_{2, t} \\
0 \text { if } b M_{t} s+x_{1, t}<\left[1-(1-b) M_{t} s\right] x_{2, t}
\end{array}\right.
$$

where $b \in[0,1]$. This case can be viewed as giving the win advantage both an additive component, on the lefthand side of (20), and a multiplicative component on the righthand side. In the terminology of Konrad (2002), such an additive advantage is a headstart for player 1, while the multiplicative disadvantage is a handicap for player 2 . This set-up collapses to our earlier case when $b=1$. The higher is $b$, the more of the win advantage comes as a headstart and correspondingly less as a handicap.

We impose the following restriction on parameters:

$$
s(T-1)<\frac{v}{b+v(1-b)},
$$

which is a modification of (1) to the present case. Note that, for $b<1$, (21) is stricter than (1) if and only if $v>1$, and that it reduces to (1) when $b=1$.

With this restriction, we can carry out an analysis parallel to the one we have above. In particular, the restriction allows us to use Lemma A.1 
in the Appendix, which extends our Proposition 1 and extends a result of Konrad (2002).

For an illustration, consider the case of $T=3$ with the win advantage creating both a headstart and a handicap, such as in (20). In contest 3, in case of symmetry, $M_{3}=0$, each player's expected effort is $\frac{v}{2}$, and his expected net payoff is zero. In case of asymmetry in that contest, $M_{3}=2$. By Lemma A.1, the expected payoff to the leader is $2 s[b+v(1-b)]$.

Consider next contest 2 . Here, there is a leader for sure, with $M_{1}=1$. The value of winning is

$$
a_{2}=2 s[b+v(1-b)] .
$$

The leader's expected net surplus is

$$
z+a+v(1-w)=3 s[b+v(1-b)] .
$$

Thus, in contest 1 , the value of winning is the above plus the prize in that contest, $v$, that is,

$$
v+3 s[b+v(1-b)] .
$$

Note that, at $b=1$, this becomes $v+3 s$. Moreover, this value increases as $b$ decreases, i.e., as more weight is put on handicapping relative to headstart, if and only if $v>1$. Each player's expected effort in contest 1 is

$$
\frac{1}{2}\{v+3 s[b+v(1-b)]\} .
$$

Corollary 2 still holds in this setting, by Corollary A.2 in the Appendix, since also now $a_{T}=0$. However, other results cannot be expected to carry over to the present case without further conditions. Consider, for example, Corollary 7 on the relative efforts of the players in the second contest of a three-contest game. Combining Corollary A.2 in the Appendix with the expression for the value of winning the second contest, in (22) above, we find that the laggard has the larger expected efforts in the second contest if and only if

$$
s>\frac{v^{2}(1-b)}{[b+v(1-b)]^{2}} .
$$

This puts a lower limit on the win advantage in order for the laggard to exert more effort than the leader in the second contest of a three-contest game. Combining this with the upper limit in (21), we have in fact that a value for the win advantage $s$, satisfying both the constraints in (21) and (23) when $b<1$, can only exist when $v<\frac{b}{1-b}$. In fact, when $v>\frac{b}{1-b}$, the opposite of Corollary 7 is true: the leader has the higher expected efforts in the second contest of a three-contest game. 


\subsection{Discounting}

We so far simplified the analysis by disregarding players' discounting of future payoffs. Suppose, alternatively, that the players use a common discount factor $\delta \in(0,1]$. As shown in the Appendix, the leader's extra value of winning in contest $t$ now is

$$
a_{t}=2 s \frac{1-\delta^{T-t}}{1-\delta}
$$

which is increasing in $\delta$ for $t \leq T-2$ and approaching $2 s(T-t)$ as $\delta$ approaches 1 .

In Proposition 2, this implies that the laggard's expected effort in contest $t$, rather than (13), becomes

$$
E x_{2, t}^{*}\left(M_{t}\right)=\frac{v^{2}-\left(M_{t} s\right)^{2}}{2\left[v+2 s \frac{1-\delta^{T-t}}{1-\delta}\right]} ;
$$

thus, the more discounting, the higher is the laggard's expected efforts for contests $t \leq T-2$. The leader's expected payoff in contest $t$, in (14), becomes, from (A11) in the Appendix,

$$
E u_{1, t}^{*}\left(M_{t}\right)=\frac{s}{1-\delta}\left\{M_{t}\left(1-\delta^{T-t}\right)+\delta\left[\frac{1-\delta^{T-t}}{1-\delta}+\delta^{T-t}(T-t)\right]\right\} .
$$

Note that, as before, $a_{T}=0$ and $a_{T-1}=2 s$, so that Corollaries 2 and 7 still hold. Corollary 6 is modified, in that the condition in (18) becomes

$$
\frac{1-\delta^{T-t}}{1-\delta}<\frac{v M_{t}}{v-M_{t} s}
$$

Thus, we can add heavy discounting to the factors, discussed in Section 5, leading to the laggard having more expected effort than the leader.

\subsection{Varying prizes}

In the main analysis, we assume that there is a prize of value $v$ in each contest. Allowing this prize to vary across the contests does not have a too strong effect on the outcome of the game so long as the contest prize in each contest, denoted $v_{t}$, still adhers to condition (1) so that, for each contest $t, v_{t} \geq s(T-1)$. If this is not the case, there is a possibility that the leader's lead will be so great that the laggard concedes and the players exert no effort at all in one or more of the contests, in line with part (i) of Proposition 1.

In order to explore the possible outcomes when prizes vary, consider the case of $T=3$. Let $v_{t} \geq 0$ be the prize in contest $t \in\{1,2,3\}$. Suppose 


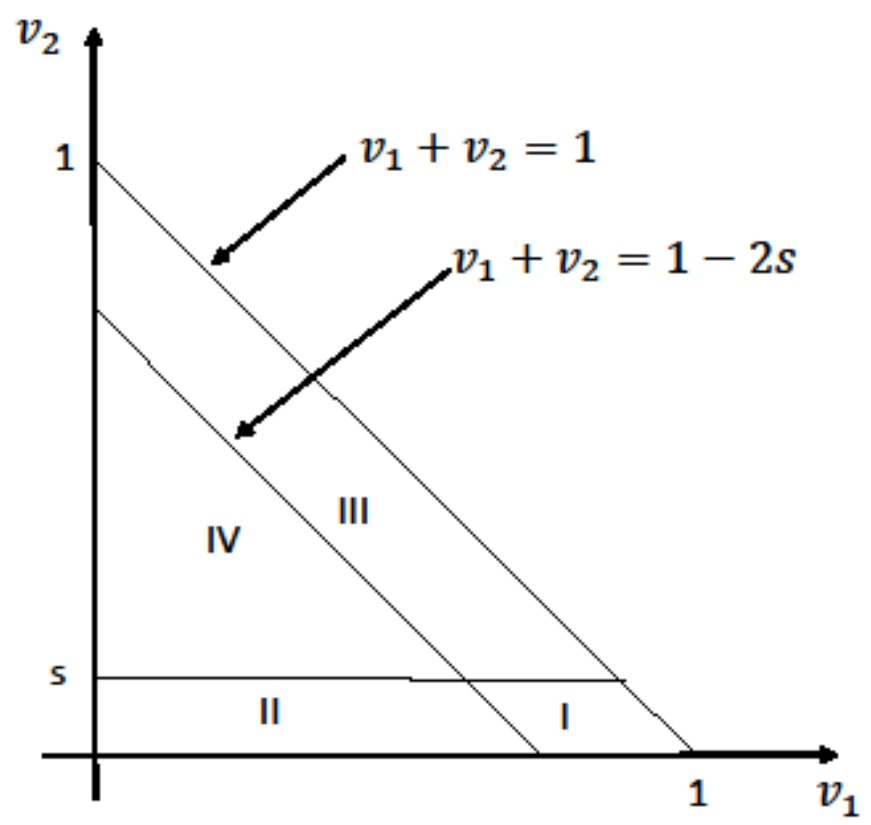

Figure 3: Varying prizes.

the contest designer has a total budget of 1 to spend in total in the three contests, so that $v_{1}+v_{2}+v_{3}=1$, implying $v_{3}=1-v_{1}-v_{2}$, and assume that $s \in\left(0, \frac{1}{6}\right)$.

The equilibrium outcome of this game is illustrated in Figure 3, which describes the distribution of prizes in $\left(v_{1}, v_{2}\right)$ space; given the fixed total prize budget, the third prize, $v_{3}=1-v_{1}-v_{2}$, is measured by the distance from the $v_{1}+v_{2}=1$ line. Details of the analysis of this case are in the Appendix. We can delineate four different areas in Figure 3 in which the game is played out differently.

If $1-v_{1}-2 s \leq v_{2} \leq s$, so that we are in area I of Figure 3, then each player exerts expected effort of $\frac{1}{2}$ in contest 1 , while no efforts are exerted in contests 2 and 3 , so that total expected effort in the game is 1 . In this case, both $v_{2}$ and $v_{3}$ are so small, relative to the win advantage $s$, that they are not worth fighting for for the player losing contest 1.

If $v_{2}<1-v_{1}-2 s$ at the same time as $v_{2} \leq s$, so that we are in area II in Figure 3, then each player's expected effort in contest 1 is $\left(v_{1}+v_{2}+2 s\right) / 2$. In contest 2, no player exerts effort and the leader wins that contest for certain. In contest 3 , however, both the leader and the laggard exert positive expected efforts with a total expected effort of $1-v_{1}-v_{2}-2 s$. Thus, total expected effort across the three contests is again 1 . In this case, it is $v_{1}$ and $v_{2}$ that are small. Efforts are exerted in contest 1, mainly in order to obtain the win advantage and get in position before the showdown in contest 3 , where the big prize is. 
If $v_{2} \geq 1-v_{1}-2 s$, as well as $v_{2}>s$, so that we are in area III in Figure 3 , then each player exerts in expectation $\left(1-v_{2}+s\right) / 2$ in contest 1 . In contest 2, expected efforts of leader and laggard are

$$
\frac{\left(v_{2}-s\right)^{2}}{2 v_{2}} \text { and } \frac{v_{2}^{2}-s^{2}}{2\left(1-v_{1}\right)}
$$

respectively. Now, two possibilities arise. One is that the laggard wins contest 2 , so that the game is back to symmetry in contest 3 with total expected effort at $1-v_{1}-v_{2}$. The other possibility is another win by the leader, increasing his accumulated win advantage so much that he wins contest 3 without further efforts. As shown in the Appendix, when taking into account the win probabilities in contest 2 , we find that the total expected effort in this game is again 1 . In this case, $v_{2}$ is big enough for there being something to fight for in contest 2 , while $v_{3}$ is so small that the laggard's incentives disappear in the event of a second loss.

Finally, the case of $s<v_{2}<1-v_{1}-2 s$ corresponds to area IV in Figure 3 and covers that of $v_{1}=v_{2}=v_{3}=\frac{1}{3}$ discussed in the main analysis. Each player's expected effort in contest 1 is $\left(v_{1}+3 s\right) / 2$. In contest 2 , expected efforts of the leader and the laggard are

$$
\frac{\left(v_{2}-s\right)^{2}}{2 v_{2}} \text { and } \frac{v_{2}^{2}-s^{2}}{2\left(v_{2}+2 s\right)},
$$

respectively. In contest 3 , if the laggard wins in contest 2 , then the game is at symmetry and total expected efforts of the players are $1-v_{1}-v_{2}$. If the leader wins again in contest 2 , then, in contest 3 , the leader has a $2 s$ win advantage and total expected efforts in that contest are $1-v_{1}-v_{2}-2 s$. Again, as shown in the Appendix, total expected efforts in the game are 1. In this case, both $v_{2}$ and $v_{3}$ are large enough that a player has incentives to stay in the game throughout, even if he should lose both contest 1 and contest 2 .

In summary, we find that the outcome of the game that we have discussed in our main analysis is relatively robust to variations in prizes, as long as later prizes do not become too small. It appears that the assumption in (1) can be replaced with the weaker condition $s(t-1)<v_{t}$, for each $t$. Thus, for example, any $v_{1}>0$ in the first contest can be allowed.

\subsection{Long games}

We have so far insisted on a game of finite length. In particular, we have assumed that the game is over after $T$ contests, where $T<\frac{v}{s}+1$. If this assumption no longer holds, we have to deal with the possibility that the leader's cumulated wins are so many that he can win again with exerting 
no effort, a phenomenon we saw also in Section 6.3 above. When the stage prize is constant at $v$ across time, the state where one player wins without efforts is absorbing and the game will stay in that state throughout.

In order to explore the consequences of win advantages in long games, we go to the extreme case and consider the case of infinitely long games, i.e., where $T=\infty$. Moreover, we assume, as in Section 6.2, that players discount future payoffs with a discount factor $\delta \in(0,1)$. The value for the leader of reaching a state when he will win all future contests effortlessly is thus $V:=\frac{v}{1-\delta}$. We will stick to an upper limit on the win advantage, though, by assuming that $s<v$.

The value for the leader of winning has so far been denoted $a_{t}$ and in the analysis above, it has been found to be independent of the leader's net number of wins, $M_{t}$. This is no longer the case in an infinite game. Define $t^{*}$ as the first contest at which a player can possibly win effortlessly, i.e., $t^{*}:=\left\lceil\frac{v}{s}+1\right\rceil$. This is also the number of net wins needed in order to achieve the endless streak of effortless wins. Define the number of additional net wins needed for the leader to achieve this as $L_{t}=t^{*}-M_{t}$.

Consider some contest $t^{\prime} \geq t^{*}-1$ in which the leader is one win shy of this endless streak, i.e., where $L_{t^{\prime}}=1$. The value of winning for the leader will be $\delta V=\frac{\delta v}{1-\delta}$. Using (6), we find that the laggard's expected effort is somewhere in the interval $\left[0, s(1-\delta)\left(1-\frac{s}{2 v}\right)\right)$, depending on where in the interval $\left(\frac{v}{s}, \frac{v}{s}+1\right]$ we have $M_{t^{\prime}}$. Clearly, with the de facto end of the game looming ahead, the laggard is severely discouraged. This will also affect contests in which $L_{t}$ is greater than 1 , i.e., where $M_{t}$ is less than $t^{*}-1$.

This analysis, although incomplete, serves to illustrate that, in infinite games with win advantages, we obtain an effect similar to that of races, or best-of- $t$ competitions. Long games create a race-like incentive to rush for the big prize $V$. And our result in Corollary 2, that the laggard eventually has the more effort, clearly does not hold for long games.

\section{Conclusion}

In this paper we have examined a finite series of all-pay auctions that are linked through time. Specifically, a player who has won more contests than he has lost is assumed to build up a win advantage over the rival, and the more net wins the larger the advantage. In the contest literature, one can say that we endogenize the size of any headstart. The effect captured here may be purely psychological or experience-based, but may also be due to factors outside of the model such as sellers who gain more back-room resources, or researchers with more assistants. The series of contests has a symmetric outset, and we identify effects overlooked in static contest mod- 
els. Two effects are at work that influence efforts of leaders and laggards. First, a headstart leads both players to exert lower effort in expectation, but affects the laggard most; exerting effort will at best even up the contest, at which point both players will expend much resources to gain the lead. Second, the headstart creates an extra value to the leader by ensuring easier access to future prizes, hence reducing the effort of the laggard further. The relative magnitude of these effects change throughout the series of contests, however, so that, eventually, the laggard has the higher expected effort.

In the series of contests, the whole value of the prize is competed away, as is common in all-pay auctions with a symmetric starting point. The players fight intensely when the contest is even so that there appears to be overdissipation of the prize in these cases. However, the magnitude of the resource exertion in these cases reduces the further advanced we are in the sequence of contests. There are fewer future prizes to be won in this case, making the value of being the leader lower.

We have focussed on cases in which the laggard may be expected to exert most effort, and find this to be most likely when he is at a large disadvantage (due to the leader relaxing), or when there are few contests remaining (since the value of remaining the leader diminishes). Due to the latter effect, the laggard will always be expected to exert most effort in the final contest. We can also show that as long as the sequence is long enough (specifically, at least four contests), the laggard will be expected to have most effort before the final contest. Should he subsequently lose in spite of this, the laggard will have more effort than the leader in the following contest.

We have indeed been able to identify various patterns of expected effort. For example, the loser of a very uneven contest will have more effort in the subsequent contest whether he is leader or laggard. Even a player who loses all previous contests will be expected to have larger effort than the rival at some stage before the final contest as long as the series is long enough. These results are in contrast to the race literature in which a disadvantaged player will often simply give up.

We have considered several extensions to out main model to look at the robustness of our conclusions. Whereas our main model defines the win advantage as being in the form of a headstart, we investigate an extension in which the advantage may be a handicap, or a combination of headstart and handicap. The laggard can still have a higher effort than the leader in expectation, and this is more likely for a larger handicap, paralleling our previous result. The results of our main model are robust to discounting, but introducing the possibility of an infinite sequence of contests makes our model more like a race in which an absorbing state may be reached in which the laggard gives up. Finally, we show in an example that the restriction 
on having an identical prize in each contest can be relaxed, and that our results are robust as long as later prizes are not too small (in which case the laggard would again give up). Our future work will examine this line of enquiry further.

\section{A Appendix}

\section{A.1 Proof of Proposition 2}

Consider contest $T-1$. If $M_{T-1} \geq 1$, then the expected payoffs in this contest are

$$
\begin{aligned}
E u_{1, T-1}\left(M_{T-1}\right)= & p_{1, T-1}\left[v+E u_{1, T}\left(M_{T-1}+1\right)\right] \\
& +\left(1-p_{1, T-1}\right) E u_{1, T}\left(M_{T-1}-1\right)-x_{1, T-1} \\
= & E u_{1, T}\left(M_{T-1}-1\right) \\
& +p_{1, T-1}\left[v+E u_{1, T}\left(M_{T-1}+1\right)-E u_{1, T}\left(M_{T-1}-1\right)\right]-x_{1, T-1} \\
E u_{2, T-1}\left(M_{T-1}\right)= & \left(1-p_{1, T-1}\right) v-x_{2, T-1}
\end{aligned}
$$

Through the win advantage, player 1 has a guaranteed payoff of $E u_{1, T}\left(M_{T-1}-1\right)$ if he loses contest $T-1$. If player 1 wins contest $T-1$, then he gets the instantaneous prize $v$ and the continuation value in contest $T$, with $M_{T}=M_{T-1}+1$. Should player 1 lose contest $T-1$, then he gets no instantaneous prize but receives the continuation value from the net number of wins $M_{T}=M_{T-1}-1$ in the next contest.

Since $M_{T-1} \geq 1$, we have that, if player 2 wins, he receives the instantaneous prize $v$, and the net win for player 1 is $M_{T-1}-1 \geq 0$ in contest $T$; the continuation value for player 2 is zero in the final contest anyway.

The extra value to player 1 from winning contest $T-1$ is thus given by $E u_{1, T}\left(M_{T-1}+1\right)-E u_{1, T}\left(M_{T-1}-1\right)$; commensurate with the notation in Section 3 , denote this extra value to winning by $a_{T-1}$. Using the results for contest $T$ in the text, we have that $a_{T-1}=2 s$; note that this is independent of the number of net wins in this contest. From Proposition 1, we now find expected efforts and payoffs in contest $T-1$ as

$$
\begin{aligned}
E x_{1, T-1}\left(M_{T-1}\right) & =\frac{\left(v-M_{T-1} s\right)^{2}}{2 v} \\
E x_{2, T-1}\left(M_{T-1}\right) & =\frac{v^{2}-\left(M_{T-1} s\right)^{2}}{2(v+2 s)} \\
E u_{1, T-1}\left(M_{T-1}\right) & =E u_{1, T}\left(M_{T-1}-1\right)+\left(M_{T-1}+2\right) s \\
& =\left(M_{T-1}-1\right) s+\left(M_{T-1}+2\right) s \\
& =\left(2 M_{T-1}+1\right) s \\
E u_{2, T-1}\left(M_{T-1}\right) & =0
\end{aligned}
$$


Using (7), we can stipulate the form of the equilibrium expected payoff for player 1 in contest $t$ to be:

$$
\begin{aligned}
E u_{1, t}^{*}\left(M_{t}\right) & =E u_{1, t+1}\left(M_{t}-1\right)+a_{t}+M_{t} s \\
& =E u_{1, t+1}\left(M_{t}+1\right)+M_{t} s
\end{aligned}
$$

Calculating the expected payoffs recursively backwards reveals a pattern for the equilibrium expected payoff in each contest

$$
\begin{aligned}
E u_{1, T}\left(M_{T}\right)= & M_{T} s \\
E u_{1, T-1}\left(M_{T-1}\right)= & \left(2 M_{T-1}+1\right) s \\
E u_{1, T-2}\left(M_{T-2}\right)= & \left(3 M_{T-2}+3\right) s \\
E u_{1, T-3}\left(M_{T-3}\right)= & \left(4 M_{T-3}+6\right) s \\
& \cdot \\
& \cdot \\
E u_{1, t}\left(M_{t}\right)= & s\left[\sum_{j=0}^{T-t}\left(M_{t}+j\right)\right]=s\left[(T-t+1) M_{t}+\sum_{j=1}^{T-t} j\right]
\end{aligned}
$$

This is rewritten in the more convenient form (14) in the Proposition.

In order to examine the equilibrium expected efforts for the advantaged and disadvantaged player, we simply need to identify the parameters in (6) for each contest. The bias term $z$ is $M_{t} s$, and we need to calculate the difference to the leader from winning and losing the current contest, $a_{t}$.

It is convenient to consider how $a_{t}$ is determined using (14). From (10), we have:

$$
a_{t}=E u_{1, t+1}\left(M_{t}+1\right)-E u_{1, t+1}\left(M_{t}-1\right) .
$$

From (14), we have

$$
E u_{1, t+1}\left(M_{t+1}\right)=s(T-t) M_{t+1}+\frac{1}{2}(T-t-1) .
$$

Applying (A3) in (A2), replacing $M_{t+1}$ by first $M_{t}+1$ and then $M_{t}-1$, gives

$$
\begin{aligned}
a_{t} & =s(T-t)\left[\left(M_{t}+1\right)-\left(M_{t}-1\right)\right] \\
& =2 s(T-t) .
\end{aligned}
$$

Putting $z=M_{t} s$ and $a=a_{t}$ into (6) gives the expected efforts in the Proposition.

In order to verify (15), we have, from (14), that

$$
E u_{1, t}^{*}(1)=s(T-t+1)\left(1+\frac{1}{2}(T-t)\right) .
$$


From the text before the Proposition, we have that each player's expected effort at $M_{t}=0$ is

$$
\begin{aligned}
\frac{1}{2}\left[v+E u_{i, t+1}(1)\right] & =\frac{1}{2}\left\{v+s[T-(t+1)+1]\left[1+\frac{1}{2}[T-(t+1)]\right]\right\} \\
& =\frac{1}{2}\left[v+\frac{1}{2} s(T-t)(T-t+1)\right],
\end{aligned}
$$

where the first equality is by the above expression; this proves (15).

\section{A.2 Proof of Corollary 4}

Part (i): With $M_{t}=0$, total expected effort in contest $t$ is, by equation $(15)$,

$$
v+\frac{1}{2} s(T-t)(T-t+1)>v,
$$

where the inequality follows from $t<T$.

Part (ii): It follows that, after a winner is declared in contest $t$, we have $M_{t+1}=1$. Total expected efforts in contest $t+1$ are found from equations (12) and (13):

$\frac{(v-s)^{2}}{2 v}+\frac{v^{2}-s^{2}}{2[v+2(T-t-1) s]}=(v-s)\left[\frac{v^{2}+(v-s)(T-t-1) s}{v^{2}+2 v(T-t-1) s}\right]<v-s$.

Since $2 v>v-s$, the fraction within square brackets in the second expression is less than 1 , and the inequality follows.

\section{A.3 Proof of Proposition 3}

Part (i). The laggard has more expected effort if condition (18) is fulfilled. This is least likely to be satisfied for $M_{t}=1$, in which case the condition can be written as

$$
t>T-\frac{v}{v-s}
$$

Clearly, $T-\frac{v}{v-s}<T-1$, since $\frac{v}{v-s}>1$.

Part (ii). The laggard having more expected effort means, from (18), that

$$
M_{t}[v+s(T-t)]-v(T-t)>0 .
$$

If the laggard loses, then $M_{t+1}=M_{t}+1$, and the left hand side of the inequality for contest $t+1$ can be written as

$$
\begin{aligned}
\left(M_{t}+1\right)[v+s(T-t-1)]-v(T-t-1) & = \\
{\left[M_{t}(v+s(T-t))-v(T-t)\right]+\left[2 v-M_{t} s\right]+s(T-t-1) } & >0
\end{aligned}
$$


where the inequality follows since the first square-bracketed term is positive by (A4), and the second one is positive by (1).

Part (iii). In contest $t$, we have $M_{t}[v+s(T-t)]-v(T-t)<0$, since the leader has more effort in this period. By the leader losing we get $M_{t+1}=M_{t}-1$, and the left hand side of the inequality for period $t+1$ becomes

$$
\begin{aligned}
\left(M_{t}-1\right)[v+s(T-t-1)]-v(T-t-1) & = \\
{\left[M_{t}(v+s(T-t))-v(T-t)\right]-M_{t} s-s(T-t-1) } & <0 .
\end{aligned}
$$

Part (iv). If the laggard has more effort in contest $t$, then

$$
T-t<\frac{v M_{t}}{v-M_{t} s},
$$

by (18). If the laggard wins this contest, then $M_{t+1}=M_{t}-1$, and the leader has more effort in contest $t+1$ if

$$
T-t-1>\frac{v\left(M_{t}-1\right)}{v-\left(M_{t}-1\right) s} .
$$

For the inequalities in (A5) and (A6) to be consistent, we must have

$$
\begin{aligned}
\frac{v\left(M_{t}-1\right)}{v-\left(M_{t}-1\right) s}+1 & <\frac{v M_{t}}{v-M_{t} s} \Longleftrightarrow \\
\frac{v\left(M_{t}-1\right)}{v-\left(M_{t}-1\right) s}-\frac{v\left(M_{t}-1\right)+M_{t} s}{v-M_{t} s} & <0 \Longleftrightarrow \\
s \frac{v\left(M_{t}-1\right)+\left[v-\left(M_{t}-1\right) s\right] M_{t}}{\left[v-\left(M_{t}-1\right) s\right]\left(v-M_{t} s\right)} & >0,
\end{aligned}
$$

which is clearly true, by (1).

\section{A.4 Proof of Proposition 4}

Let $M_{t}=t-1$.

Part (i). The leader's expected effort in (12) is now $\frac{[v-(t-1) s]^{2}}{2 v}$, which is decreasing in $t$ by (1).

Part (ii). The laggard's expected effort in (13) is now

$$
\frac{v^{2}-(t-1)^{2} s^{2}}{2[v+2(T-t) s]} \text {. }
$$

Differentiating this expression with respect to $t$, we get

$$
\frac{s^{3}(t-1)(2 T-t-1)}{(v+2 T s-2 s t)^{2}}\left[\frac{v}{s(t-1)} \frac{v-s(t-1)}{s(2 T-t-1)}-1\right] .
$$

This is positive if the expression inside square brackets is positive, which is the case if both fractions in that expression are greater than one. The first fraction is greater than one by (1). The second fraction is also greater than one, as long as (19) holds. 


\section{A.5 Proof of Proposition 5}

Part (i). Consider contest $t$, and suppose player 2 has lost all the previous $t-1$ contest, so that $m_{t}=M_{t}=t-1$. The difference in effort between leader and laggard is, from Proposition 2,

$$
\begin{aligned}
& E x_{1, t}^{*}(t-1)-E x_{2, t}^{*}(t-1) \\
= & \frac{[v-(t-1) s]^{2}}{2 v}-\frac{v^{2}-(t-1)^{2} s^{2}}{2[v+2(T-t) s]} \\
= & \frac{s[v-s(t-1)]}{v[v+2 s(T-t)]}\left\{s t^{2}-[s(T+1)+2 v] t+[v+T(s+v)]\right\}
\end{aligned}
$$

By the assumption in (1), $v-s(t-1)>0$. It follows that the above expression has the same sign as the one inside curly brackets. Disregarding for now that $t$ is integer, that expression, in turn, is a convex function of $t$, with negative slope and positive value at zero. It thus has two real roots in $t$, both positive, which we call $\bar{t}>\underline{t}>0$. Moreover, $E x_{1, t}^{*}(t-1)-$ $E x_{2, t}^{*}(t-1)<0$ if and only if $\bar{t}>t>\underline{t}$.

In order to prove the Proposition, we need to show that $\bar{t}>T$, and that $2<\underline{t}<T-1$. It is readily verified that

$$
\begin{aligned}
& \bar{t}=\frac{1}{2 s}\left[2 v+s(T+1)+\sqrt{s^{2}(T-1)^{2}+4 v^{2}}\right], \text { and } \\
& \underline{t}=\frac{1}{2 s}\left[2 v+s(T+1)-\sqrt{s^{2}(T-1)^{2}+4 v^{2}}\right] .
\end{aligned}
$$

We first show that $\bar{t}>T$. Consider

$$
\begin{aligned}
\bar{t} & >T \\
& \Longleftrightarrow \frac{1}{2 s}\left[2 v+s(T+1)+\sqrt{s^{2}(T-1)^{2}+4 v^{2}}\right]-T>0 \\
& \Longleftrightarrow \frac{1}{2 s}\left[2 v-s(T-1)+\sqrt{s^{2}(T-1)^{2}+4 v^{2}}\right]>0 \\
& \Longleftrightarrow \sqrt{s^{2}(T-1)^{2}+4 v^{2}}+2 v>s(T-1)
\end{aligned}
$$

By (1), the right-hand-side of the inequality is at most $v$, whilst the lefthand-side is at least $4 v$. Hence $\bar{t}>T$.

We next show that $\underline{t}<T-1$. Consider

$$
\begin{aligned}
T-1 & >\underline{t} \\
& \Longleftrightarrow T-1-\frac{1}{2 s}\left[2 v+s(T+1)-\sqrt{s^{2}(T-1)^{2}+4 v^{2}}\right]>0 \\
& \Longleftrightarrow \frac{1}{2 s}\left[-2 v+s(T-3)+\sqrt{s^{2}(T-1)^{2}+4 v^{2}}\right]>0 \\
& \Longleftrightarrow s(T-3)+\sqrt{s^{2}(T-1)^{2}+4 v^{2}}>2 v
\end{aligned}
$$


where $\sqrt{s^{2}(T-1)^{2}+4 v^{2}} \geq 2 v$ and $T \geq 5$, so the inequality holds.

We finally show that $\underline{t}>2$. Consider

$$
\begin{aligned}
\underline{t} & >2 \\
& \Longleftrightarrow \frac{1}{2 s}\left[2 v+(T+1) s-\sqrt{s^{2}(T-1)^{2}+4 v^{2}}\right]-2>0 \\
& \Longleftrightarrow \frac{1}{2 s}\left[2 v+(T-3) s-\sqrt{s^{2}(T-1)^{2}+4 v^{2}}\right]>0
\end{aligned}
$$

In the Proposition we have $T \geq 5$. Let

$$
\Phi(s, T, v):=2 v+(T-3) s-\sqrt{s^{2}(T-1)^{2}+4 v^{2}} .
$$

Note that $\Phi$ is continuous in $s$, that $\Phi(0, T, v)=\Phi\left(v \frac{T-3}{T-2}, T, v\right)=0$, and that $\Phi(s, T, v)>0$ for $v \frac{T-3}{T-2}>s>0$. By (1), we have $\frac{v}{T-1}>s$. Since $v \frac{T-3}{T-2}>v \frac{1}{T-1}$ for any $T \geq 5$, we have $\Phi(s, T, v)>0$ for permissible parameter values, proving $\underline{t}>2$.

It follows that $2<\underline{t}<T-1$. This must also hold if we make the restriction to integer values. Thus, $\widehat{t} \in\{3, \ldots, T-2\}$.

Part (ii). Differentiations in (A7) give $\frac{\partial t}{\partial s}<0$ and $\frac{\partial t}{\partial T}>0$. Moreover, $\frac{\partial t}{\partial T}=$ $\frac{1}{2} \frac{\sqrt{s^{2}(T-1)^{2}+4 v^{2}}-(T-1) s}{\sqrt{s^{2}(T-1)^{2}+4 v^{2}}}$, which can be verified to lie within the interval $(0,1)$. With the restriction to integer values, the signs of the differentials still hold, although weakly so.

\section{A.6 Headstart vs handicap}

We present, and prove, a Lemma used in the discussion of headstart vs handicap in Section 6.1. The Lemma extends Proposition 1 to allow for handicaps as well has headstarts; by putting $w=1$ in (A8), we are back to $(3)$.

Lemma A.1 Let the contest success function be

$$
p_{1, t}=\left\{\begin{array}{l}
1 \text { if } z+x_{1, t}>w x_{2, t} \\
\frac{1}{2} \text { if } z+x_{1, t}=w x_{2, t} \\
0 \text { if } z+x_{1, t}<w x_{2, t}
\end{array}\right.
$$

where $z \geq 0$ and $w \in(0,1]$. Let the values of the prize be $v_{1}=v+a$ and $v_{2}=v$ for players 1 and 2 , respectively, where $v>\frac{z}{w}$, and $a \geq 0$. The unique symmetric equilibrium is as follows:

$$
\begin{aligned}
& F_{1}(0)=\frac{z}{v w} ; \quad F_{1}\left(x_{1}\right)=\frac{z+x_{1}}{v w}, \quad x_{1} \in[0, v w-z] ; \\
& F_{2}(0)=\frac{v(1-w)+a+z}{v+a} ; \quad F_{2}\left(x_{2}\right)=\frac{v(1-w)+a+w x_{2}}{v+a}, \quad x_{2} \in\left[\frac{z}{w}, v\right] .
\end{aligned}
$$


Expected efforts are

$$
E x_{1}=\frac{(v w-z)^{2}}{2 v w}, \text { and } E x_{2}=\frac{v^{2} w^{2}-z^{2}}{2 w(v+a)} ;
$$

expected net surpluses are

$$
E \pi_{1}=z+a+(1-w) v, \text { and } E \pi_{2}=0
$$

and probabilities of winning are

$$
p_{1}^{*}=1-\frac{v^{2} w^{2}-z^{2}}{2 v w(v+a)}, \text { and } p_{2}^{*}=\frac{v^{2} w^{2}-z^{2}}{2 v w(v+a)} .
$$

Proof. Player 2 will not spend more than $v$, so that the maximum spent by player 1 is $w v-z$. If player 1 sets $x_{1}=0$, then he wins if $z>w x_{2}$ so that player 2 will not choose positive effort below $\frac{z}{w}$. Hence, $x_{1} \in[0, w v-z]$, and $x_{2} \in\{0\} \cup\left[\frac{z}{w}, v\right]$. By setting $x_{1}=w v-z$, player 1 wins with probability 1 and secures a payoff of $z+a+(1-w) v$, whilst player 2 must expect 0 . The expected payoff of player 1 is

$$
E \pi_{1}=\operatorname{Pr}\left(x_{2}<\frac{z+x_{1}}{w}\right)(v+a)-x_{1}=z+a+(1-w) v .
$$

Write $X=\frac{z+x_{1}}{w}$, so that (A9) becomes

$$
\begin{aligned}
E \pi_{1} & =\operatorname{Pr}\left(x_{2}<X\right)(v+a)-(w X-z) \\
& =F_{2}(X)(v+a)-(w X-z)=z+a+(1-w) v
\end{aligned}
$$

Solving gives

$$
F_{2}(X)=\frac{v(1-w)+a+w X}{v+a} .
$$

Similarly, for player 2,

$$
\begin{aligned}
E \pi_{2} & =\operatorname{Pr}\left(x_{1}<w x_{2}-z\right) v-x_{2}=0 \\
& =F_{1}(Y) v-\frac{Y+z}{w}=0,
\end{aligned}
$$

where $Y=w x_{2}-z$. Hence,

$$
F_{1}(Y)=\frac{Y+z}{v w}
$$

Player 2's probability of winning is found from the equation $p_{2} v-E x_{2}=0$, while that of player 1 is $p_{1}=1-p_{2}$.

This result extends Lemma 1 of Konrad (2002). In order to retain his result, put $a=0$. The parallel to Corollary 1 is the following: 
Corollary A.2 With the contest success function in (A8), the disadvantaged player has the higher expected effort if

$$
a<\frac{2 v z}{v w-z} .
$$

The right-hand side in (A10) decreases in $w$. Thus, the laggard has more effort than his rival when the handicap is high, i.e., $w$ is low.

\section{A.7 Discounting}

Suppose players discount future payoffs with a discount factor $\delta \in(0,1]$. Discounting will affect the leader's expected value of winning in a straightforward manner: equation (A1), in the proof of Proposition 2, now becomes

$$
E u_{1, t}\left(M_{t}\right)=s\left(\sum_{i=0}^{T-t} \delta^{i}\left(M_{t}+i\right)\right)
$$

Using (10) and (A11), we have, for $\delta \in(0,1)$,

$$
\begin{aligned}
a_{t} & =E u_{1, t+1}\left(M_{t}+1\right)-E u_{1, t+1}\left(M_{t}-1\right) \\
& =s\left[\sum_{i=0}^{T-t-1} \delta^{i}\left(M_{t}+1+i\right)-\sum_{i=0}^{T-t-1} \delta^{i}\left(M_{t}-1+i\right)\right] \\
& =2 s \frac{1-\delta^{T-t}}{1-\delta} .
\end{aligned}
$$

Note that $\lim _{\delta \rightarrow 1} \frac{1-\delta^{T-t}}{1-\delta}=T-t$, that $\frac{d a_{t}}{d \delta}>0$ - heavier discounting means a lower value of winning for the leader - and that, as before, $\frac{d a_{t}}{d(T-t)}>0-$ the more periods left, the higher is $a_{t}$.

\section{A.8 Varying prizes}

Here we present details of the analysis of the case when prizes vary over time, discussed in Section 6.3. We start with considering the last contest, $t=3$. There are two possibilities, either symmetry, with one win to each player in the previous rounds, or asymmetry, with one player having won both previous rounds. In case of symmetry, $M_{3}=0$, each player's expected effort is $v_{3} / 2=\left(1-v_{1}-v_{2}\right) / 2$, and each player's expected net payoff is zero.

In case of asymmetry, $M_{3}=2$. We need to distinguish between two cases. If $v_{3}=1-v_{1}-v_{2} \leq 2 s$, then, by part (i) of Proposition 1, players have zero efforts in the last contest and the leader is certain to win, with net payoff $1-v_{1}-v_{2}$ to the leader and zero to the laggard. Otherwise, if 
$1-v_{1}-v_{2}>2 s$, then, by (6), the expected efforts of the leader and the laggard are

$$
\frac{\left(1-v_{1}-v_{2}-2 s\right)^{2}}{2\left(1-v_{1}-v_{2}\right)} \text { and } \frac{\left(1-v_{1}-v_{2}\right)^{2}-4 s^{2}}{2\left(1-v_{1}-v_{2}\right)}
$$

respectively, so that total expected efforts in contest 3 in this case, the sum of the two expressions above, is

$$
1-v_{1}-v_{2}-2 s
$$

The expected net payoffs are $2 s$ to the leader and, again, zero to the laggard.

Consider next the next-to-last contest, that is, $t=2$. In this case, there is surely asymmetry, with $M_{2}=1$. Again, we need to consider two possibilities. If $v_{2} \leq s$, then players have zero efforts and the leader wins contest 2 . If, in addition, $1-v_{1}-v_{2} \leq 2 s$, then the leader wins also contest 3 with zero efforts. Thus, if $1-v_{1}-2 s \leq v_{2} \leq s$, which can only happen if $v_{1} \geq 1-3 s$, then the winner of contest 1 wins the next two contests without spending further efforts and the expected value of winning contest 1 is 1 ; the variable restrictions in this case corresponds to area I in Figure 3 , where feasible combinations of $\left(v_{1}, v_{2}\right)$ are depicted. If $v_{2}<1-v_{1}-2 s$ at the same time as $v_{2} \leq s$, however, then the winner of contest 1 wins again in contest 2 and has an expected net payoff of $2 s$ in contest 3 , with a total value of winning contest 1 of $v_{1}+v_{2}+2 s<1$; this is area II in Figure 3.

If $v_{2}>s$, then, by (6), the expected efforts of the leader and the laggard are

$$
\frac{\left(v_{2}-s\right)^{2}}{2 v_{2}} \text { and } \frac{v_{2}^{2}-s^{2}}{2\left(v_{2}+a_{2}\right)},
$$

respectively. To get any further, we need to find $a_{2}$. For this, we distinguish two subcases.

If $v_{2} \geq 1-v_{1}-2 s$, as well as $v_{2}>s$, then the leader, if he wins also here, will win again in contest 3 without efforts, so $a_{2}=1-v_{1}-v_{2} \leq 2 s$, the laggard's expected effort is

$$
\frac{v_{2}^{2}-s^{2}}{2\left(1-v_{1}\right)}
$$

and total expected effort in contest 2 is

$$
\frac{v_{2}-s}{2 v_{2}\left(1-v_{1}\right)}\left[v_{2}^{2}+\left(1-v_{1}+s\right) v_{2}-s\left(1-v_{1}\right)\right] .
$$

The expected payoff to the leader is $z+a$, which here is $1-v_{1}-v_{2}+s$. Thus, the value of winning contest 1 is, in this case, $v_{1}+\left(1-v_{1}-v_{2}+s\right)=$ $1-\left(v_{2}-s\right)<1$. The case corresponds to area III in Figure 3. 
If, on the other hand, $s<v_{2}<1-v_{1}-2 s$, which can only happen if $v_{1}<1-3 s$, then $a_{2}=2 s$ by equation (17), the laggard's expected effort is

$$
\frac{v_{2}^{2}-s^{2}}{2\left(v_{2}+2 s\right)}
$$

and total expected effort in contest 2 is

$$
\frac{v_{2}-s}{v_{2}\left(v_{2}+2 s\right)}\left(v_{2}^{2}+s v_{2}-s^{2}\right) \text {. }
$$

The expected payoff to the leader is $z+a=3 s$, and the value of winning contest 1 is $v_{1}+3 s<1$. This case corresponds to area IV in Figure 3 .

Finally, consider the full game, noting that, at contest 1, there is symmetry and $M_{1}=0$. We can now specify the equilibrium play in each of the four cases introduced above. If $1-v_{1}-2 s \leq v_{2} \leq s$, then the value of winning contest 1 is 1 , and each player exerts expected effort in that contest equal to $\frac{1}{2}$. No efforts are exerted in contests 2 and 3 , so that total expected effort in the game is 1 . This is area I in Figure 3.

If $v_{2}<1-v_{1}-2 s$ at the same time as $v_{2} \leq s$, then the value of winning contest 1 is $v_{1}+v_{2}+2 s$, each player's expected effort in contest 1 is $\left(v_{1}+v_{2}+2 s\right) / 2$, and total expected effort in contest 1 is $v_{1}+v_{2}+2 s$. In contest 2 , no player exerts effort and the leader wins that contest for certain. In contest 3 , the expected efforts of leader and laggard are given in (A12), and total expected effort is $1-v_{1}-v_{2}-2 s$. Thus, total expected effort across the three contests is 1 . This is area II in Figure 3.

If $v_{2} \geq 1-v_{1}-2 s$, as well as $v_{2}>s$, then the value of winning contest 1 is $1-\left(v_{2}-s\right)$. Each player exerts in expectation $\left[1-\left(v_{2}-s\right)\right] / 2$ in contest 1 , and total expected effort in that contest is $1-\left(v_{2}-s\right)$. In contest 2 , the expected efforts of leader and laggard are

$$
\frac{\left(v_{2}-s\right)^{2}}{2 v_{2}} \text { and } \frac{v_{2}^{2}-s^{2}}{2\left(1-v_{1}\right)},
$$

respectively, with total expected effort given by (A13). The laggard wins with probability

$$
\frac{v_{2}^{2}-s^{2}}{2 v_{2}\left(1-v_{1}\right)}
$$

in which case the game moves to symmetry in contest 3 where each player's expected effort is $\left(1-v_{1}-v_{2}\right) / 2$, with total expected efforts in contest 3 equal to $1-v_{1}-v_{2}$. With probability

$$
1-\frac{v_{2}^{2}-s^{2}}{2 v_{2}\left(1-v_{1}\right)},
$$


the leader wins contest 2, in which case no effort is exerted in contest 3 and the leader wins for sure. The total expected effort across all contests is

$$
\begin{aligned}
& 1-\left(v_{2}-s\right)+\frac{v_{2}-s}{2 v_{2}\left(1-v_{1}\right)}\left[v_{2}^{2}+\right.\left.\left(1-v_{1}+s\right) v_{2}-s\left(1-v_{1}\right)\right] \\
&+\frac{v_{2}^{2}-s^{2}}{2 v_{2}\left(1-v_{1}\right)}\left(1-v_{1}-v_{2}\right)=1 .
\end{aligned}
$$

This is area III in Figure 3.

Finally, consider the case $s<v_{2}<1-v_{1}-2 s$, which covers the special case of $v_{1}=v_{2}=\frac{1}{3}$ discussed in Section 4 . The value of winning contest 1 is $v_{1}+3 s$, and so each player's expected effort in contest 1 is $\left(v_{1}+3 s\right) / 2$ with a total expected effort in contest 1 of $v_{1}+3 s$. In contest 2 , expected efforts of the leader and the laggard are

$$
\frac{\left(v_{2}-s\right)^{2}}{2 v_{2}} \text { and } \frac{v_{2}^{2}-s^{2}}{2\left(v_{2}+2 s\right)},
$$

respectively, with total expected effort given in (A14). The laggard wins with probability

$$
\frac{v_{2}^{2}-s^{2}}{2 v_{2}\left(v_{2}+2 s\right)},
$$

in which case there is symmetry in contest 3 and total expected effort in that contest equal to $1-v_{1}-v_{2}$. The leader wins contest 2 with probability

$$
1-\frac{v_{2}^{2}-s^{2}}{2 v_{2}\left(v_{2}+2 s\right)},
$$

and the game moves to an instance of asymmetry in contest 3 with the players' expected efforts in that contest given in (A12) and total expected efforts equal to $1-v_{1}-v_{2}-2 s$. The total expected effort across all three contests is

$$
\begin{aligned}
v_{1}+3 s+\frac{v_{2}-s}{v_{2}\left(v_{2}+2 s\right)}\left(v_{2}^{2}\right. & \left.+s v_{2}-s^{2}\right)+\frac{v_{2}^{2}-s^{2}}{2 v_{2}\left(v_{2}+2 s\right)}\left(1-v_{1}-v_{2}\right) \\
+ & {\left[1-\frac{v_{2}^{2}-s^{2}}{2 v_{2}\left(v_{2}+2 s\right)}\right]\left(1-v_{1}-v_{2}-2 s\right)=1 . }
\end{aligned}
$$

This is area IV in Figure 3.

\section{References}

Berger, J. and D. Pope (2011), "Can Losing Lead to Winning?", Management Science 57, 817-827. 
Clark, D.J. and T. Nilssen (2013), "Learning by Doing in Contests", Public Choice 156, 329-343.

Clark, D.J., T. Nilssen, and J.Y. Sand (2015), "Motivating over Time: Dynamic Win Effects in Sequential Contests", unpublished manuscript.

Clark, D.J. and C. Riis (1995), "Social Welfare and a Rent-Seeking Paradox", Memorandum 23/1995, Department of Economics, University of Oslo.

Farrell, S. and A.R. Hakstian (2001), "Improving Salesforce Performance: A Meta-Analytic Investigation of the Effectiveness and Utility of Personnel Selection Procedures and Training Interventions", Psychology \& Marketing 18, 281-316.

Konrad, K.A., (2002), "Investment in the Absence of Property Rights: The Role of Incumbency Advantages", European Economic Review 46, 1521-1537.

Konrad, K.A. (2009), Strategy and Dynamics in Contests. Oxford University Press.

Konrad, K. A. and D. Kovenock (2009), "Multi-Battle Contests", Games and Economic Behavior 66, 256-274.

Krishnamoorthy, A., S. Misra, and A. Prasad (2005), "Scheduling Sales Force Training: Theory and Evidence", International Journal of Research in Marketing 22, 427-440.

Krumer, A. (2013), "Best-of-Two Contests with Psychological Effects", Theory and Decision 75, 85-100.

Megidish, R. and A. Sela (2014), "Sequential Contests with Synergy and Budget Constraints", Social Choice and Welfare 42, 215-243.

Mehlum, H. and K.O. Moene (2006), "Fighting against the Odds", Economics of Governance 7, 75-87.

Mehlum, H. and K.O. Moene (2008), "King of the Hill: Positional Dynamics in Contests", Memorandum 6/2008, Department of Economics, University of Oslo.

Ofek, E. and M. Sarvary (2003), "R\&D, Marketing, and the Success of Next-Generation Products", Marketing Science 22, 355-270.

Reeve, J., B.C. Olson, and S.G. Cole (1985), "Motivation and Performance: Two Consequences of Winning and Losing in Competition", Motivation and Emotion 9, 291-298. 
Skiera, B. and S. Albers (1998), "COSTA: Contribution Optimizing Sales Territory Alignment", Marketing Science 17, 196-213.

Tong, K. and K. Leung (2002), "Tournament as a Motivational Strategy: Extension to Dynamic Situations with Uncertain Duration", Journal of Economic Psychology 23, 399-420.

Vansteenkiste, M. and E.L. Deci (2003), "Competitively Contingent Rewards and Intrinsic Motivation: Can Losers Remain Motivated?", Motivation and Emotion 27, 273-299. 